\title{
Investigating the Determinant and Impact of Digital Library Engagement: A Conceptual Framework
}

\author{
Mohamad Rahimi Mohamad Rosman ${ }^{1}$, Mohd Nasir Ismail ${ }^{2}$, Mohamad Noorman Masrek \\ ${ }^{1}$ Faculty of Information Management \\ Universiti Teknologi MARA \\ Kelantan Branch, Machang Campus \\ 18500 Machang, Kelantan \\ Malaysia \\ rahimimr@uitm.edu.my \\ ${ }^{2}$ Faculty of Information Management \\ Universiti Teknologi MARA \\ Kelantan Branch, Machang Campus \\ 18500 Machang, Kelantan \\ Malaysia \\ nasir733@uitm.edu.my \\ ${ }^{3}$ Faculty of Information Management \\ Universiti Teknologi MARA \\ Shah Alam, Puncak Perdana Campus \\ No. 1, Jalan Pulau Angsa AU10/A \\ Section U10, 40150 Shah Alam \\ mnoorman@uitm.edu.my
}

\begin{abstract}
Facing an unprecedented explosion and growth of Information and Communication Technology (ICT) signal the overwhelming dependency on the digital library (DL). Over the years, libraries spent a great amount of investment to subscribe to various digital resources such as online databases, electronic journals, electronic books and other digital resources. However, previous studies reported that the use of $D L$ is underutilized; hence undermining its original purposes and making it harder for the libraries to justify their investment on $D L$ resources. It is reported that users prefer to use free online resources compared to the $D L$ resources. The lack of $D L$ usage is credited to the lack of $D L$ engagement and the impact of contextual factors leading to DL engagement. Yet, not much is known about the contributing factors of $D L$ engagement as well as its impacts. Therefore, the purpose of this paper is twofold: (1) to introduce the concept of Digital Library Engagement, and (2) to discuss at the conceptual level on the determinants and impacts of digital library engagement and development of a conceptual framework. In order to develop the conceptual framework, the study adopted a systematic literature review approach of over 100 papers. Grounded in previous literature on $D L$, the contributions of this paper are as follows: first, the paper provides insight on the new concept of digital library engagement; second, the paper proposes a con-
\end{abstract}

ceptual model for further exploration of the digital library engagement concept; finally, implications of study and future directions for research are outlined.

Subject Categories and Descriptors:

[H.3.7 Digital Libraries]; [A.1 Literature]: Introductory and Survey

General Terms: Digital Library, Digital Library Framework

Keywords: Digital Library, Engagement, Determinants of Digital Library Engagement, and Impacts of Digital Library Engagement

Received: 17 December 2018, Revised 5 March 2019, Accepted 15 March 2019

Review Metrics: Review Scale- 0/6, Review Score-4.66, Interreviewer Consisteny- 82.5\%

DOI: $10.6025 / \mathrm{jdim} / 2019 / 17 / 4 / 214-226$

\section{Introduction}

The growth of Information and Communication Technology (ICT) have spearheaded the explosion of information; 
making proper management of information an intriguing task for a librarian. More information is produced on the daily basis; such as emails, reports, electronic forms, electronic documents, videos and images, that may go beyond the control of the library's repository. More intriguingly, $80 \%$ of this information is in unstructured form (MacMillan \& Huff, 2009; Mannix, 2010; Marlin, 2005; O'Callaghan \& Smits, 2005). Consequently, Burnett, Clarke, Edwards, and Illsley (2006) estimated that users spend up to $30 \%$ of their time searching for relevant information within the organisational repository. The need to have access to relevant, timely, and up-to-date information has led to a significant uptake and investment on Digital Library $(\mathrm{DL})$ in recent years.

$\mathrm{DL}$ is a collection of organized digital documents, objects and services (Alhaji, 2009). It includes online databases, electronic journals, images, text, videos, and audio resources. Once considered an expensive investment, DL is no longer a lavish technology (Masrek \& Samadi, 2017; Samadi, 2016). The use of DL among libraries is very common nowadays (Chiong, Kiing, Ler, Lim, \& Wong, 2016; Masrek \& Samadi, 2017; Rahman, Jamaludin, \& Mahmud, 2011; Sahak \& Masrek, 2014). Every year libraries spent a great amount of investment to subscribe to various DL resources (Chiong et al., 2016; Jose, 2007; Matusiak, 2012; Sahak \& Masrek, 2014), despite its rising cost and expensiveness. The use of $D L$ is no longer an option; it a compulsory and mandatory facility among students, particularly for a postgraduate student. DL ensure a high quality of performance (Asad, Mohamad Noorman, Khalid, \& Saima, 2017; Rahman et al., 2011), reduce operating cost (Allotey \& Ojeabulu, 2011) and providing access to a variety of resources surpassing all barriers (Trivedi, 2010).

While research on the digital library has been greatly reported in the literature, gaps still exist in a number of areas. As mentioned by Masrek and Samadi (2017), due to the expensive nature of $D L$, more research is encouraged. Despite the undeniable benefits of $D L$, previous research shows that there is an underutilization of $D L$ among users (Bagudu \& Sadiq, 2013; Chiong et al., 2016; Matusiak, 2012; Sahak \& Masrek, 2014). It is found out that users prefer to use free online resources compared to universities repository of DL resources, thus undermining the value of investment put forward by the universities.

This paper is an attempt to provide a conceptual understanding of the new concept of Digital Library Engagement; as opposed to the narrow concept of digital library use that widely adopted in the previous studies on DL. In doing so, this paper identifies the determinants and impacts of DL engagement, as well as proposing a conceptual framework for future study and exploration of the field.

The rest of paper is organised as follows. In the next section, we provide a brief definition and supporting argument on the concept of digital library engagement. Then, a con- ceptual model underlying the research is presented. Next, we explain the underlying theories and evidence of variables selected for the studies. Finally, we conclude the paper and outline several limitations of our study.

\section{The concept of Digital Library Engagement}

Glancing into the previous literature of $\mathrm{DL}$, researchers proved that the use of DL brings benefits to the organization particularly on the individual, technological, and organizational levels (Asad et al., 2017; Chiong et al., 2016; Park, Roman, Lee, \& Chung, 2009; Volovici, Fratila, Bera, \& Moisil, 2017; Wan Dollah, 2006). Yet, those impacts diversify implying that the ways user use the DL may influence and predict their DL impacts. According to DeLone and McLean (1992), the levels of use may determine the net benefits or impact of the usage (either positively or negatively).

Even though many studies have been conducted on DL, it is found out that researchers had conceptualized the term 'use' as a generic term; without considering its underlying principles and the level of interaction and perception of users on the information system. In their seminal article, Masrek and Samadi (2017) suggested that there is a need to redefine the concept of DL usage by introducing the concept of $D L$ engagement. $D L$ engagement, at some extent, can be equated with usage, however, it goes beyond the generic definition of usage and it includes a multiple dimensions focusing on several aspects such as affective, cognitive, and behavioural (O'Brien \& Toms, 2010). Contrary to a generic definition of usage, DL engagement evaluates the concept of use more effectively by assessing users through four dimensions such as focus attention, felt involvement, aesthetic, and novelty. As found out by Masrek and Samadi (2017), DL engagement encourages the user to continue to use the $\mathrm{DL}$ and promotes it to their colleagues and friends. Moreover, DL engagement also a crucial part of system development that will guarantee the success of system usage (O'Brien \& Toms, 2010).

For this study, DL engagement is defined as the deep and long-time use of the DL. It involves the combined effect of the Information System (IS) concept: user participation and user involvement with the DL, as well as the extent of DL being exploited to support their purposes. Four variables underlying the DL engagement; focus attention, felt involvement, aesthetic, and novelty were adopted from the previous study of O'Brien and Toms (2010) and Masrek and Samadi (2017). To further strengthen the link between DL engagement and usage, previous theories and models of Information System (IS) may provide the answer. A DL can be considered as a subset of an IS due to its nature. DL integrate several elements of IS; such as a combination of hardware, software, telecommunication networks and management of data (Valacich \& Schneider, 2010). DL provides access to digital resources (Fox, 2002), providing contents that either stored locally or remotely (Trivedi, 2010), service 
delivery in efficient and real-time manner (Xu \& Du, 2018), storing of digital resources in digital forms (Smith, 2002), and following the appropriate lifecyle for the maintenance of a digital collection (Witten, Bainbridge, \& Nichols, 2010).

Furthermore, previous theories in IS such as Bandura (1986) Social Cognitive Theory, Davis (1989) Technology Acceptance Model, Goodhue and Thompson (1995) Task Technology Fit, Fishbein and Ajzen (1975) Theory of Reasoned Action and Ajzen (1991) and Theory of Planned Behaviour suggested that the belief, attitudes and behaviours of an individual is influenced by certain determinants; such as individual, technological, organizational, and contextual factors. These determinants then eventually mediated by individual's belief, attitude and behaviour (such as engagement) towards the certain outcome (i.e. individual performance, satisfaction, benefits). For example, individual with adequate training on DL and IS will have a strong belief that they can fully utilize the DL features to perform their task, have a strong and positive feeling towards the $\mathrm{DL}$, and show a positive behaviour to the $\mathrm{DL}$ such as promoting it usage to friends, colleagues and others. Meanwhile, lack of belief and negative attitudes, as well as negative behaviour towards the DL will lead to lack of $D L$ engagement, improve the tendencies for users to engage with other unreliable resources and undermine the value of the investment by the libraries.

In the context of Malaysian research universities, there is a scarcity of research related to the determinant and impact of DL engagement (Masrek \& Samadi, 2017). Most of the previous studies on DL were focusing on the narrow conceptualization of usage; focusing only on technological dimension. Previous studies were led by the assumption that users are expected to gain benefits because of DL engagement. However, as pointed out by Delone and McLean (2003) and Pembee (2014), the potential impacts of IS will be influenced by the levels and ways of their engagement either positively or negatively. Therefore, there are compelling needs to further confirm the new concept of $D L$ engagement especially from the perspective of post graduate students. Presently, there are not much knowledge on the determinants and impacts of $D L$ engagement and previous studies were led with a narrow conceptualization of usage. To further confirm the concept of DL engagement, the subsequent section will briefly discuss the research methodology and the development of the conceptual model for the study.

\section{Methodology}

In order to develop the conceptual framework, this study adopted a systematic literature review (SLR) approach of Webster and Watson (2002). Webster and Watson (2002) recommended that literature searches should follow the following steps: (1) literature search must start with a leading journal, (2) backward search should be conducted to consider relevant literature, and (3) forward search should be performed to determine the articles citing the literature. Therefore, this study conducted three phases analysis of literature searches, as illustrate on the following figure 1 :

The first phase starts with searching for the relevant literature related to $\mathrm{DL}$. We used the following tools: Scopus, IEEE Xplore, Science Direct, Emerald, and ProQuest. We also searched literature from top journals: Information System Research, Scientific Data, Information, Communication \& Society, Aslib Journal of Information Management, Journal of Librarianship and Information Science, Journal of Information Technology, European Journal of Information Systems, Journal of Academic Librarianship, Information and Organization, Library and Information Science Research, International Journal of Information Management, and Library \& Information Science Re-

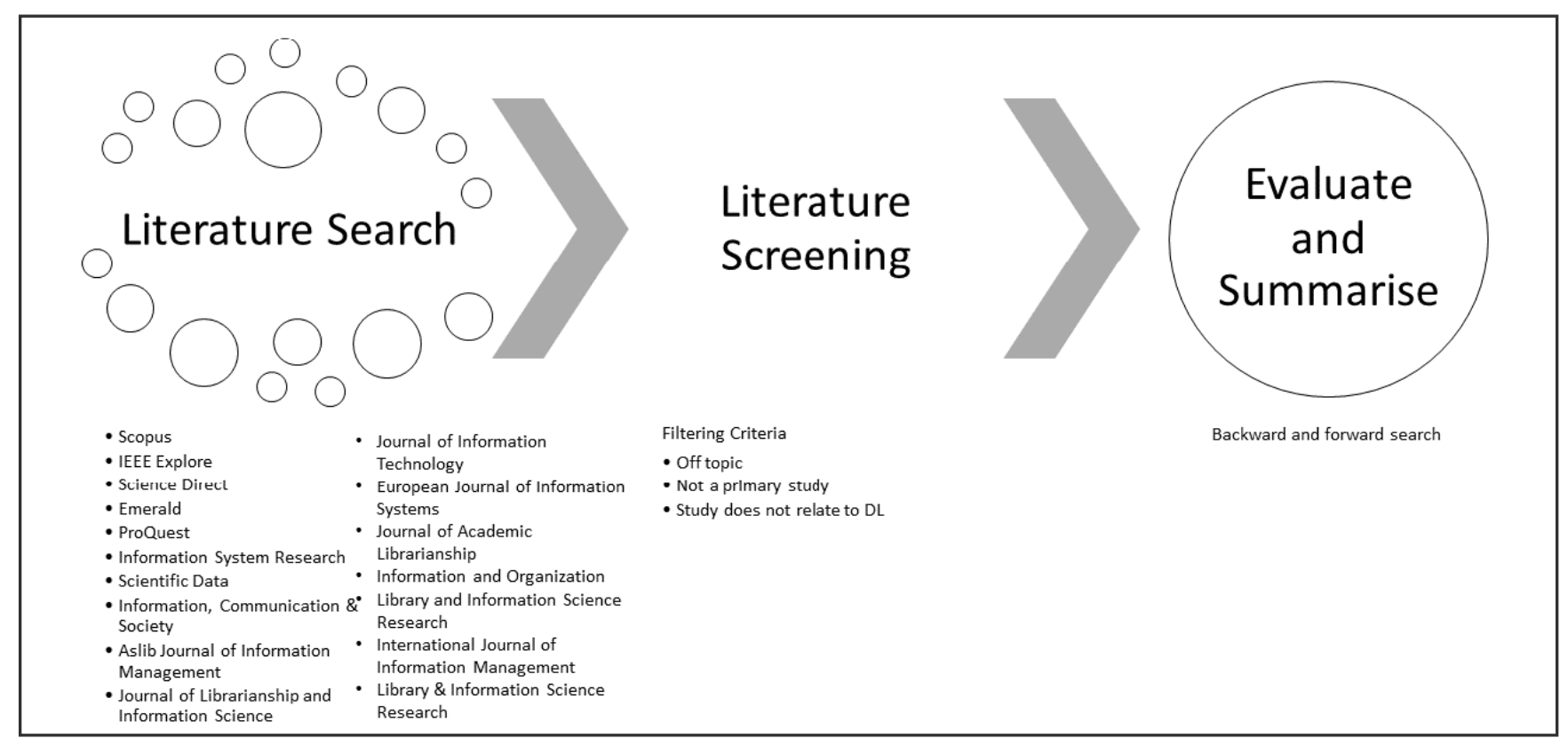

Figure 1. Literature search process 
search. The keywords used are 'digital library' AND 'use', 'electronic library' AND 'use', 'electronic resources' AND 'use', 'online resources' AND 'use', and 'digital resources' AND 'use'. Literature searches were limited to research papers, books, and theses. The total hits were recorded and exported into referencing software, EndNote X7. 502 where hits were recorded during the literature search. Next, we use the EndNote function, 'Find Duplicates' to remove any duplications of hits; thus, trimming the total hits into 471 items. Then, we manually check the list of the literature to remove any literature that was not relevant to DL. Finally, 126 papers were selected for the second phase filtering process.

For the second phase, the literature was screened; some literature was excluded due to: (1) off-topics, (2) poor quality, (3) studies do not relate to DL use. First, we skimmed through the title of the literature to determine the relevancy of the article. Then, we perform a quick analysis on the abstract. A total of 115 literature were selected for the third phase.

In the third phase, the literature was read and summarized based on Glaser and Strauss (1967) approaches. First, we skimmed the literature to determine the critical issues it tried to deliver. Then, we go deeper into the literature by focusing on the abstract, discussion, conclusion, limitation and future work. Lastly, we critically analyse each publication, summarize potential research gap and identify potential variables for the development of the conceptual framework. A backward and forward search was done to the selected publications using Thomson Reuters Web of Science and Google Scholar; and finally, 135 papers were found relevant to the topic of interest.

\section{The Proposed Model}

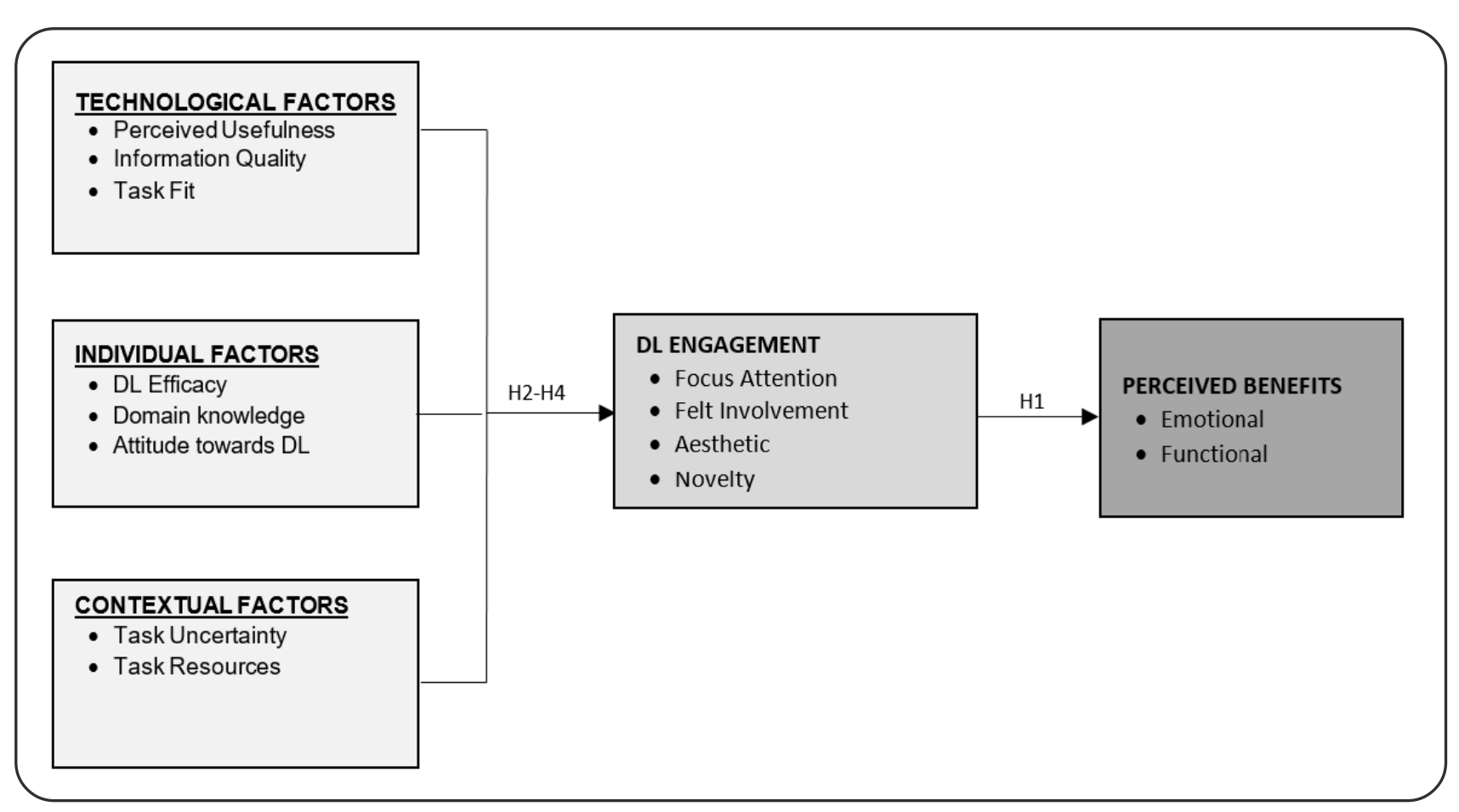

Figure 2. Conceptual framework showing the determinants and impacts of DL engagement
The following figure 2 depicts the conceptual model for the study. The model was developed based on a similar work on the concept of digital library engagement from Masrek and Samadi (2017). However, the previous model only conceptualize and tested on the concept of the DL engagement by adopting similar works of O'Brien and Toms (2010) in an e-commerce setting and has yet to identify the determinants and the impacts of DL engagement from the perspective of DL.

The resultant conceptual model for this study comprised of 14 variables grouped into five dimensions, namely technological factors, individual factors, contextual factors, DL engagement, and perceived benefits. Technological, individual, and contextual factors are the determinants or predictors for $D L$ engagement, while perceived benefits are the impacts of $\mathrm{DL}$ engagement. Organizational factors, even though found to be significant towards the DL Engagement is not considered for the study because: (1) Organization characteristics are usually related to an employee of organization and distinct factor for postgraduate students, and (2) The impact of organizational characteristics waned due to lack of knowledge about the library environment. Three variables are selected for technological factors, namely perceived usefulness, information quality, and task fit. For the individual factors, three variables selected, namely, DL efficacy, domain knowledge, and attitude towards DL. For the contextual factors, two variables are selected, namely task uncertainty and task resources. The combined effect of technological, individual, and contextual factors was expected to influence the $\mathrm{DL}$ engagement. Four variables selected for DL engagement, namely focus attention, felt involvement, aesthetic, and novelty. For the perceived benefits, two variables are selected, namely emotional and functional benefit. 
Undeniably there are other factors that can be included into the model, however, the selection of variables are chosen based on the strong support from previous studies, their applicability and suitability with the research purpose, supported by a panel of DL experts. An expert review form was distributed to a number of DL experts locally and globally. The expert panels were asked to choose a list of relevant variables based on DL literature. They were also asked to include any other variables that they think might be useful and relevant to the study. The selection of the expert panels is based on the following criteria: (1) the panel has more than 10 years of academic experience, (2) the panel has published articles related to the DL, and (3) the panel has experience of conducting a workshop or seminars on DL.

The relationship between the determinants (technological, individual, and contextual) and DL engagement are based on the previous theories and research models. For the technological factors, the relationship with DL engagement is based on the Technology Acceptance Model (TAM), Technology Acceptance Model 2 (TAM2), Unified Theory of Acceptance and Use of Technology (UTAUT), Theory of Reasoned Action (TRA), Theory of Planned Behaviour (TPB), Information System Success Model, and Task-Technology Fit (TTF). The essence of the theories posit that individual's attitude towards a behaviour (such as DL engagement and use of technology) will affect the behaviour. Attitude is operationalized differently by different authors. TAM and TAM2 use Perceived Ease of Use and Perceived Usefulness. UTAUT use Performance Expectancy and Effort Expectancy. TTF look for the fit between task and the technology that influence the outcome (utilization). Moreover, previous research also confirmed the relationship between technological factors with DL Engagement (Ali \& Money, 2005; Chen, Lambert, \& Guidry, 2010; DeLone \& McLean, 1992; Samadi, 2016; Tait \& Vessey, 1988).

The relationship between individual factors with DL Engagement is based on TRA and TPB. The theories posit that individual's behaviours (i.e. use of an information system/adoption) are driven by behavioural intention (i.e. user engagement) where the behavioural intention is driven by the attitude towards the behaviour, subjective norms, and perceived behaviour control. Previous research of Hong, Thong, Wong, and Tam (2002), Masrek, Karim, and Hussein (2007), Park et al. (2009), and Pembee (2014) also confirmed the relationship between individual factors with DL engagement.

On the other hand, the relationship between contextual factors with DL Engagement is based on Bandura (1986) Social Cognitive Theory (SCT) and Technology-Organization Environment (TOE) framework (DePietro, Wiarda, \& Fleischer, 1990). The essence of the theories posit that interaction between the environment and specific behaviour (i.e. DL engagement, use of technology) involves individuals perceptions of their environment and in turn their behaviour is relatively modified by that environment.
Previous research also confirmed the relationship between contextual factors with DL Engagement (Bakker \& Demerouti, 2008; DePietro et al., 1990; Jiang, Chen, \& Lai, 2010; Masrek et al., 2007; Pembee, 2014; Xanthopoulou, Bakker, Demerouti, \& Schaufeli, 2007, 2009).

The relationship of $D L$ Engagement with the outcome variable (Perceived Benefits) is based on TAM, TAM2, and TTF. The essence of the theories posit that performance, and subsequent use of information system depends on individual behaviour (i.e. DL engagement). Moreover, the theories also suggest that the utilization of an information system depends on how well the supporting factors (i.e. technological, individual, and contextual) fits the characteristics of the individual task (Klopping \& McKinney, 2004). Previous research also confirmed the relationship between DL Engagements and Perceived Benefits (Airila et al., 2014; Albrecht, 2012; DeLone \& McLean, 1992; Espinoza-Parra, Molero, \& Fuster-Ruizdeapodaca, 2015; Karatepe, Karadas, Azar, \& Naderiadib, 2013; Samadi, 2016; Trice \& Treacy, 1988).

\section{Perceived Benefits}

Perceived benefits are the extent to which DL helps an individual achieve a certain level of satisfaction, productivity, and personal sense of accomplishment. Over the years, study on the performance, adoption, and satisfaction of the IS have become one of the mainstream topics for research. More importantly, previous studies also proved that a deep engagement with the IS (i.e. DL) contributed to the benefits of an individual (Davis, 1989; DeLone \& McLean, 1992; Masrek \& Samadi, 2017; Samadi, 2016; Venkatesh, Morris, Davis, \& Davis, 2003).

Lassila and Brancheau (1999) highlight that there is a compelling need to manage the changes or impact brought by the implementation of new technology. The author argues that the researcher has conceptualized the impact of technology implementation rather narrowly, such as:

a. Cumulative (average usage) - The number of hours of technology use

b. Reliance - How much user depend on technology to carry out their work

c. Diversity - Number of different software features used by one or more users.

d. Context - Technology use is shaped by the context of use between technology and types of the organisations structure.

Within the context of Library and Information Science (LIS) and IS, the studies on the impact of engagement with technology is one of the mainstream topics. Several researchers have identified the dimensions of impacts to 
the individual and organization. For example, Samadi, Masrek, and Yatin (2014) evaluated the impacts from the perspective of personal accomplishment and individual satisfaction. In a similar work, Masrek and Gaskin (2016) measured the DL impact from the perspective of user satisfaction. Saracevic (2004) meanwhile produced a usability assessment of DL that are adopted by several researchers. However, it can be pointed out that previous studies on DL only focusing on user satisfaction aspect of the $\mathrm{DL}$, ignoring the emotional and functional benefits of such application. Therefore, for this study the perceived benefits will be adopted from the previous studies of Kiran and Diljit (2012) by including the emotional and functional benefits.

\subsection{Emotional Benefits}

Emotional benefit is operationalized as the extent to which an individual believes that the engagement with the DL helps them to meets their information requirements and needs (Simon, Grover, Teng, \& Whitcomb, 1996). There are many purposes to engage with the $\mathrm{DL}$. A postgraduate student and academician engage with the $D L$ to find relevant articles for the development and support of their research framework. An undergraduates student engaged with the DL to complete their assignment and improve understanding of their subject. DL provides a reliable, upto-date, and relevant sources of information to the users. Fulfilling their information needs improves their emotional satisfaction. According to Gatian (1994), emotionally satisfied users are someone who will come back to use the system.

In this context, postgraduate students use the digital library to complete their task, such as reviewing articles for the development of their research framework. Previous studies of Kiran and Diljit (2012), Masrek and Gaskin (2016), Samadi (2016), and Pembee (2014) confirmed that emotional benefit is very important in the context of $D L$.

\subsection{Functional Benefits}

Functional benefit is operationalized as the feeling of worth during and after the interaction with the DL (Kiran \& Diljit, 2012). User engages with an information system to perform a certain task that usually difficult to be performed manually. DL provides individuals with more technical tools and assistive capabilities to speed up information searching and gathering. In today academic setting, a postgraduate student needs a holistic and rigours approaches. Due to the competitive nature of postgraduate education, these students are not only accessed by certain coursework and a written thesis, but it goes beyond that scope; some include innovative contributions such as creation or modification of new and novel ideas. Moreover, certain supervisors may require their students to participate in innovation competition, presenting papers in a conferences and journals, as well as participate in an academic colloquium.

To find support for the relationship between DL engagement and functional benefits, previous studies have shown that an engagement with the information system (i.e. DL) led into the improvement of personal satisfaction which improve the individual personal sense of accomplishment (Bakker \& Demerouti, 2008; Samadi, 2016).

\section{Digital Library Engagement}

DL engagement sometimes can be equated to usage, however, it goes beyond the normal conceptualization of usage by including multiple dimensions focusing on several aspects such as affective, cognitive, and behavioural (O'Brien \& Toms, 2010). DL engagement is considered as an important predictor of information system success (Baroudi, Olson, \& Ives, 1986; Hwang \& Thorn, 1999; O'Brien \& Toms, 2010). Masrek and Samadi (2017) found out that an individual engaged in $\mathrm{DL}$ will be loyal to the information system, as well as suggesting it to their colleagues and friends.

From the perspective of IS, engagement can be considered as dual-factors; user participation and user involvement (Baroudi et al., 1986; Hwang \& Thorn, 1999). Between the two factors, user involvement is considered as the strongest predictor of information system success (Hwang \& Thorn, 1999). The term 'user involvement, which relates to the mental or psychological state of users towards the information system and its development process can be equated to the concept of DL engagement currently proposed by this paper.

From the psychological perspective of work engagement, engagement is defined as a positive, fulfilling, work-relate state of mind that is characterized by vigour, dedication, and absorption. Rather than a momentary and specific state, engagement refers to a more persistent and pervasive affective-cognitive state that is not focused on any particular object, event, individual, or behaviour (Schaufeli, Bakker, \& Salanova, 2006, p. 4).

Psychologist always consider engagement as the opposite of a burnout; engagement as a positive pole while burnout as the negative pole (Maslach \& Leiter, 1997). An engaged individual will go extra miles to perform the jobs, self-motivated, exercise influence over events that affect their lives, creating their own positive feedback, selfappreciation, and consider working as a fun process (Bakker \& Demerouti, 2008).

For this study, four variables adopted from the previous study of Masrek and Samadi (2017) and O'Brien and Toms (2010) such as felt involvement, focus attention, novelty, and aesthetic are considered. Focus attention is defined as a concentration of mental activity by focussing on a single stimulus and ignoring all others. It measures how well an individual engages with certain medium (i.e. DL). Felt involvement meanwhile define as the extent of how much fun users' were having during the interaction and how drawn. Aesthetic is defined as the visual beauty or the study of natural and pleasing (or aesthetic) computer based environments. On the other hand, novelty refers to features of the interface that users find unexpected, sur- 
prising, new, and unfamiliar.

In the context of postgraduate students, the advancement of IS have led into Industrial Revolution 4.0 (IR4) in which many resources are now available digitally and online. Being postgraduate students, they need to access to many resources for the development of their research framework, find supporting theories and model, as well as completing their coursework assignments. Since postgraduate study consists of fulltime and part-time students, finding resources through the DL is the best way. Most students have limited time and difficulties to visit the physical library; therefore DL should be their best choice. However, certain factors influence their level of engagement with the DL. The DL should be able to draw attention of the users, interesting to use, have a good graphical user interface (GUI) and provides new features that can attract user attention. Lacking these criteria may lead to poor DL engagement; as shown by previous research, in which users prefer to engage with free online resources rather than the institution subscribed DL resources. The lack of DL engagement causes under-utilization of resources, poor quality of research output, as well as underwhelming the investment of the institutions to subscribe to these expensive resources. Fulfilling user needs led into satisfaction; emotionally and functionally. Previous studies have also shown that DL engagement has a direct impact on perceived benefits (Baroudi et al., 1986; Kiran \& Diljit, 2012; Samadi, 2016). Therefore, it can be hypothesized that:

H1: DL engagement has a significant and positive relationship with perceived benefits.

\section{Determinants}

Determinant or antecedent is conceptualized as the possible factors that influence or predict the outcome variable (i.e. DL engagement). From the extensive review on DL literature, it can be summarized that most of the determinants are focussing on technological factors (Ali \& Money, 2005; Hong et al., 2002; Park et al., 2009; Pembee, 2014; Rahman et al., 2011; Thong, Hong, \& Tam, 2002; Trice \& Treacy, 1988), organisational factors (Ali \& Money, 2005; Dahlan, Karia, Asaari, Ramayah, \& Lee, 2006; Masrek et al., 2007; Thong et al., 2002), and individual factors (Ali \& Money, 2005; Hong et al., 2002; Masrek et al., 2007; Park et al., 2009; Pembee, 2014; Rahman et al., 2011; Samadi, 2016; Thong et al., 2002; Trice \& Treacy, 1988).

However, gaps are identified from the previous study; first, lack of attention towards the contextual factors. Second, previous studies conceptualize the concept of usage rather narrowly. Third, there is a crucial need to explain the under-utilization of DL resources reported by several authors over the years (Chiong et al., 2016; Matusiak, 2012; Sahak \& Masrek, 2014; Samadi, 2016). Authors cite lack of DL engagement (Masrek \& Samadi, 2017) and lack of knowledge on contextual factors (Jiang et al., 2010; Kai-ming
Au \& Enderwick, 2000) as possible factors for underutilization of DL resources. For the purpose of this study, three determinants selected; technological, individual, and contextual factors. Technological and individual factors are selected to be in line with the previous research on DL, while contextual factors to address the gap within the field. Other determinants, although significant, will not be addressed in this study.

\subsection{Technological Factors}

Technological factors is one of the most research and significant factors within the DL domain. Several authors have proved that these factors are very crucial for the utilization of DL. Technological factors is defined as the extent of perceived usefulness, information quality, and task fit influence individuals towards DL engagement and its subsequent impacts. It also refers to the characteristics of the digital library that affect their DL engagement. Three variables selected from the previous study within the DL and IS domain; perceived usefulness, information quality, and task fit.

\section{Perceived Usefulness}

Perceived usefulness is operationalized as the degree to which a person believes that using the digital library would enhance his or her job performance (Davis, 1989). Previous studies proved that perceived usefulness is one of the predictors of DL engagement (Baroudi et al., 1986; Davis, 1989; Hong et al., 2002; Ramayah \& Aafaqi, 2004; Thong et al., 2002; Vaidyanathan, Sabbaghi, \& Bargellini, 2005; Venkatesh et al., 2003).

Having a good system promotes engagement with such a system. In the context of postgraduate students, they engage with the DL to complete their works; they need a good system that easy to use and reliable. A complicated, system will lead to dissatisfaction; in psychological term it will lead to burnout. For a student who enrols in 2-3 years studies, a favourable first impression will determine whether to use or not to use the information system (i.e. DL).

\section{Information Quality}

Information quality is defined as the extent of users' perception of a DL's information which is provided to support their information needs. Information quality concern on the reliability of the information provided by the DL. Comparing to the open source resources, DL resources usually comes from a reputable commercial and academic publisher. Open access resources, even though reliable, however sometimes these resources are not based on the highest standard of academic publication. The importance of information quality as a predictor for DL engagement have been confirmed by several researchers (Ahn, Ryu, \& Han, 2004; DeLone \& McLean, 1992; Masrek \& Gaskin, 2016; Masrek, Jamaludin, \& Awang Mukhtar, 2010; Rahman et al., 2011; Vaidyanathan et al., 2005).

\section{Task fit}


Task fit is defined as how well DL functionalities fits the needs and requirements of the users. Having a fit between task and technology contributed to DL engagement motivates the users to extensively engaging themselves with the DL. In the context of a postgraduate students, the nature of the study requires them to make references to high quality of resources such as journals, proceeding, and indexed publications. Henceforth, DL is considered as the best IS to fulfil their needs. Moreover, previous studies also confirmed the relationship between task fit and DL engagement (Ali \& Money, 2005; Goodhue \& Thompson, 1995).

In summary, previous studies have proved that technological factors (perceived usefulness, information quality, and task fit) lead to DL Engagement. Therefore, it is hypothesized that:

$\mathrm{H} 2$ : Technological factors have significant and positively relationship with $\mathrm{DL}$ engagement.

\subsection{Individual Factors}

Individual factors are believed to be the most relevant factors to both IS success as well as to human computer interaction $(\mathrm{HCl})$ research (Hong et al., 2002). Three variables are selected for the study; DL efficacy, domain knowledge, and attitude towards DL.

\section{Efficacy}

DL efficacy is operationalized as the degree of confidence in one's ability to perform a particular task (Agarwal \& Karahanna, 2000). The importance of DL efficacy has been documented in various studies (Thong et al., 2002). Prior research on IS and LIS found that DL efficacy has a positive impact on DL engagement (Hong et al., 2002; Masrek, 2007; Ramayah \& Aafaqi, 2004; Samadi et al., 2014; Thong et al., 2002). Individuals with a high level of DL efficacy shows more tendency on using the DL and are more persistent to overcome all difficulties while dealing with the DL features (Johnson, Ferguson, \& Lester, 1999). For example, Thong et al. (2002) found out that DL efficacy can help students to gain confidence while engaging with the DL. Moreover, the earlier they get access and knowledge to the application, the easier for them to be familiar with the application.

\section{Domain Knowledge}

Domain knowledge is operationalized as users' background knowledge of search domain (Hong et al., 2002). The importance of domain knowledge towards DL engagement cannot be denied. User's knowledge on their domain determines the tendency to engage or disengage with the DL (Thong et al., 2002). Marchionini (1990) suggests that domain expert can perform the search more quickly, focused and efficient, compared to the novices. This is supported by Koohang (2004) argument that those with the experience in using the Internet will have a positive learning experience compared to those who did not have prior experience. Thong et al. (2002) listed three possible reasons for the domain knowledge effect: (1) those with high domain knowledge have the capability to separate from relevant and irrelevant information, (2) prior domain knowledge helps to facilitate the learning of search principles, and (3) domain knowledge expert is capable to utilize technical terminology in formulating queries, as well as capable to make a sound judgment over the sources.

\section{Attitude towards DL}

Attitude towards DL is operationalized as the tendency of users to respond positively or negatively to the DL. Masrek (2007) defined attitude towards DL as the individual's positive or negative feelings about performing a behaviour. For example, if a person perceived that performing certain behaviour (i.e. engaging with the $D L$ ) will bring a positive outcome, he or she will have a positive attitude towards the behaviour. For example, Samadi et al. (2014) found out that attitude towards DL is found to be critical in determining usage behaviour of DL engagement. Previous research also confirmed a positive relationship between attitude towards DL and DL engagement (Alqasa, Mohd Isa, Othman, \& Zolait, 2014; Poude, Zamani, \& Abedi, 2011; Samadi et al., 2014).

Therefore, based on the above arguments, it is hypotheses that:

H3: Individual factors have a significant and positive relationship with DL engagement.

\subsection{Contextual Factors}

Contextual factors is operationalized as the external factors that affect the DL engagement and its perceived benefits. A glance into DL literature shown that contextual factors are being neglected. Two variables are selected for the purpose of the study; task uncertainty, and task resources.

\section{Task Uncertainty}

Task uncertainty is defined as the degree to which the specific requirements or intermediate outcomes associated with a task or activity cannot be anticipated or forecast (Rustagi, King, \& Kirsch, 2008).

Contrary to undergraduate education, postgraduate education requires the students to complete the task or assignment on their own. Supervisors and colleagues act as supporting actor along the journey. The complexity of task differs between students; and different interpretation among academician/ supervising panels. Therefore, engagement with DL may ease the level of uncertainty of the task and enhance its quality. The more complex task requires more dependency towards the DL.

\section{Task Resources}

Task resources is defined as the extent of physical, psychological, or social aspects of the task that are either functional or dysfunctional in achieving work goals (Schaufeli et al., 2006). Bakker and Demerouti (2008) suggested that task resources, such as colleagues sup- 
port, supervisor support, performance feedback, opportunity for learning, autonomy, and opportunity to enhance personal skills are positively associated with user engagement as well as enhance the potential benefits of its acceptance. These resources are good for an individual.

In the context of postgraduate students, writing a thesis, publishing a paper, and innovation competition requires utmost support from their surroundings. Colleagues offered an understanding of the ideas and sharing of research information. Supervisors supervise and monitor the student progress and make recommendation and suggestion if necessary. These resources are very crucial for a postgraduate student. In such, DL offered a variety of resources to the students to complete their task. These resources can be accessed using a personal computer or portable device.

Moreover, being the highest level of education (especially doctorate study) require them to produce a high quality of research, supported by rigorous and valid arguments. The DL may reduce the hardship to meet those task demand by providing access to a variety of high-quality journals and proceedings. Moreover, meeting dateline is another factor that may encourage postgraduate students to engage with the DL. As a prerequisite for graduation, postgraduate students need to publish at least two papers in a reputable journal, as well as conference proceedings. Meeting this requirement is a difficult task, as the peer reviewing process usually very rigorous and demanding.

Therefore, based on the above arguments, it is hypotheses that:

$\mathrm{H} 4$ : Contextual factors have a significant and positive relationship with DL engagement.

\subsection{Mapping of research objectives and hypotheses} The following table 1 below shows the mapping between

\begin{tabular}{|c|c|c|c|}
\hline Research Objectives & Variables Tested & Hypotheses & $\begin{array}{l}\text { Supporting } \\
\text { Theories \& Models }\end{array}$ \\
\hline $\begin{array}{l}\text { To examine the level of user en- } \\
\text { gagement with the DL measured } \\
\text { in terms of focus attention, felt } \\
\text { involvement, aesthetic and nov- } \\
\text { elty }\end{array}$ & $\begin{array}{l}\text { DL Engagement } \\
\text { - Focus Attention } \\
\text { - Felt Involvement } \\
\text { - Aesthetic } \\
\text { - Novelty }\end{array}$ & Not applicable & $\begin{array}{l}\text { - Models: Masrek and } \\
\text { Samadi (2017), O'Brien and } \\
\text { Toms (2010) }\end{array}$ \\
\hline $\begin{array}{l}\text { To identify the users' emotional } \\
\text { and functional impacts DL en- } \\
\text { gagement. }\end{array}$ & $\begin{array}{l}\text { DL Engagement } \\
\text { - Focus Attention } \\
\text { - Felt Involvement } \\
\text { - Aesthetic } \\
\text { - Novelty } \\
\text { Perceived Benefits } \\
\text { - Emotional } \\
\text { - Functional }\end{array}$ & $\begin{array}{l}\mathrm{H} 1 \text { : Engagement has a } \\
\text { significant and positive } \\
\text { relationship with } \\
\text { perceived benefits }\end{array}$ & $\begin{array}{l}\text { - Theories: TAM, TAM2, } \\
\text { TTF } \\
\text { - Models: Kiran \& Diljit } \\
\text { (2012), DeLone \& } \\
\text { McLean (1992) }\end{array}$ \\
\hline $\begin{array}{l}\text { To identify whether technologi- } \\
\text { cal factors, individual factors, } \\
\text { and contextual factors jointly } \\
\text { predict DL engagement. }\end{array}$ & $\begin{array}{l}\text { Technological Factors } \\
\text { - Perceived Usefulness } \\
\text { - Information Quality } \\
\text { - Task Fit } \\
\text { Individual Factors } \\
\text { - DL Efficacy } \\
\text { - Domain Knowledge } \\
\text { - Attitude towards DL } \\
\text { Contextual Factors } \\
\text { - Task Uncertainty } \\
\text { - Task Resources } \\
\text { DL Engagement } \\
\text { - Focus Attention } \\
\text { - Felt Involvement } \\
\text { - Aesthetic } \\
\text { - Novelty }\end{array}$ & $\begin{array}{l}\text { H2: Technological } \\
\text { factors has a significant } \\
\text { and positive relationship } \\
\text { with DL engagement } \\
\text { H3: Individual factors } \\
\text { has a significant and } \\
\text { positive relationship } \\
\text { with DL engagement } \\
\text { H4: Contextual factors } \\
\text { has a significant and } \\
\text { positive relationship } \\
\text { with DL engagement }\end{array}$ & $\begin{array}{l}\text { Theories: TAM, TAM2, } \\
\text { UTAUT, SCT } \\
\text { Models: DeLone \& McLean } \\
\text { (1992), Ali and ey (2005), } \\
\text { Masrek (2007), Samadi } \\
\text { (2016) }\end{array}$ \\
\hline
\end{tabular}

Table 1. Mapping of RO and Hypotheses 
the research objectives and hypotheses that will be addressed in this study, as well as the supporting theories and models.

Based on table 1, there are three objectives that will be addressed in this study:

a. To examine the level of user engagement with the $\mathrm{DL}$ measured in terms of focus attention, felt involvement, aesthetic and novelty.

b. To identify the users' emotional and functional impacts of DL engagement.

c. To identify whether technological factors, individual factors, and contextual factors jointly predict $\mathrm{DL}$ engagement.

\section{Conclusion}

In this paper, we have conducted an extensive and structured literature review on the topic of DL. In total, 135 publications were analysed. Then, we introduced the new concept of digital library engagement, as an extension of the conventional concept of digital library usage. Subsequently, we proposed a conceptual model of the determinants and impacts of digital library engagement. Finally, implications, future direction, and limitations of the study were outlined.

In order to validate our research-in-progress, the next step in this research is data collection. To confirm our hypothesis, a quantitative study will be conducted. A survey research methodology will be adopted for the study. A structured questionnaire will be distributed to the target respondents. The research will be conducted in the uncontrived setting. The unit of analysis is individual (i.e. postgraduate students) who use the DL to complete their job. Data will be collected through the printed and online questionnaire. The items of the questionnaire are adopted from previous studies. The questionnaire will be a pre-tested expert review, before data collection through a pilot study. Reliability test will be conducted to determine the reliability of the questionnaire before the actual data collection. Data collection are expected to take between two or three months, then the data will be coded and performed data cleaning. Reliability and factor analysis will be conducted, and the data will be interpreted based on the descriptive and inferential analysis.

This study will be limited in several ways. First, this study only concerns on theory generalization (i.e.postgraduate students at Malaysian research universities). Further study must be conducted to consider the whole population (i.e. postgraduate students at Malaysian public universities) for the population generalization of the theory. Second, we will only consider three types of determinants (technological, individual and contextual) of DL engagement in this study. Further research may include other determinants such as organizational and socio-economic factors.
Again, the inclusion of most of the variables is well supported by past research. However, it is yet to be tested and verified especially from the context of postgraduate student at Malaysian research universities. The proposed model should be of interest to academic institutions, practitioners, academician, DL vendors, and government policymakers. Academic institutions can utilize the model as assessment tools to justify their investment on DL technology. Practitioners can use the factors identified in this study to further improve the level of DL engagement in their institutions. Academician can use the model and concept proposed in this study to further extend the knowledge on DL. On the other hand, DL vendors may use the results to further improve the performance and effectiveness of the DL products. Government policymakers meanwhile may utilise the result from the study to devise and develop a DL policy for the nation, as well as designing curriculum for the Library and Information Science (LIS) courses.

\section{Acknowledgement}

We would like to thank the experts who were involved in the expert review process for this research project. Without their passionate participation and input, the selection and validation of the variables could not have been successfully conducted.

\section{References}

[1] Agarwal, R., Karahanna, E. (2000). Time Flies When You're Having Fun: Cognitive Absorption and Beliefs About Information Technology Usage. MIS quarterly, 24 (4) 665694.

[2] Ahn, T., Ryu, S., Han, I. (2004). The impact of the online and offline features on the user acceptance of Internet shopping malls. Electronic commerce research and applications, 3 (4) 405-420.

[3] Airila, A., Hakanen, J. J., Schaufeli, W. B., Luukkonen, R., Punakallio, A., Lusa, S. (2014). Are job and personal resources associated with work ability 10 years later? The mediating role of work engagement. Work \& Stress, 28 (1) 87-105.

[4]Ajzen, I. (1991). The theory of planned behavior. Organizational behavior and human decision processes, 50 (2) 179-211.

[5] Albrecht, S. L. (2012). The influence of job, team and organizational level resources on employee well-being, engagement, commitment and extra-role performance: Test of a model. International Journal of Manpower, 33 (7) 840-853.

[6] Alhaji, I. U. (2009). Digitization of library resources and the formation of digital libraries: a practical approach. Retrieved from http://www.academia.edu/download/46146706/ alhaji_paper.pdf

[7] Ali, A. S. B., Money, W. H. (2005, 03-06 Jan. 2005). A Study of Project Management System Acceptance. 
Paper presented at the Proceedings of the 38th Annual Hawaii International Conference on System Sciences.

[8] Allotey, D., Ojeabulu, G. (2011). Potential Benefits Organizations Derive From Using Enterprise Content Management Systems: A Study of Selected Nigerian Organizations. (Master Thesis in IT Management Master), Mälardalen University, Sweden.

[9] Alqasa, K. M., Mohd Isa, F., Othman, S. N., Zolait, A. H. S. (2014). The impact of students' attitude and subjective norm on the behavioural intention to use services of banking system. International Journal of Business Information Systems, 15 (1) 105-122.

[10] Asad, K., Mohamad Noorman, M., Khalid, M., \& Saima, Q. (2017). Factors influencing the adoption of digital reference services among the university librarians in Pakistan. The Electronic Library, 35 (6) 1225-1246. doi:10.1108/EL-05-2016-0112

[11] Bagudu, A. A., Sadiq, H. (2013). Students' Perception of Digital Library Services: A Case Study of International Islamic University, Malaysia. Library Philosophy and Practice (e-journal).

[12] Bakker, A. B., Demerouti, E. (2008). Towards a model of work engagement. Career development international, 13 (3) 209-223.

[13] Bandura, A. (1986). Social foundations of thought and action: A social cognitive theory: Englewood Cliffs, NJ, US: Prentice-Hall, Inc.

[14] Baroudi, J. J., Olson, M. H., Ives, B. (1986). An empirical study of the impact of user involvement on system usage and information satisfaction. Communications of the ACM, 29 (3) 232-238.

[15] Burnett, S., Clarke, S., Edwards, R., Illsley, R. (2006). Document collaboration: linking people, process, and content. Technology evaluation and comparison report, Butler Group.

[16] Chen, P.-S. D., Lambert, A. D., Guidry, K. R. (2010). Engaging online learners: The impact of Web-based learning technology on college student engagement. Computers \& education, 54 (4) 1222-1232.

[17] Chiong, C. P., Kiing, S. M., Ler, Y. P., Lim, Q. J., Wong, Y. J. (2016). Behavioural Intention of Undergraduates to Adopt Digital Library: An Investigation Into Private Universities in Malaysia. (Bachelor of Commerce (hons) Accounting), UTAR, Malaysia.

[18] Dahlan, N., Karia, N., Asaari, M. H. A. H., Ramayah, T., Lee, G. T. (2006). Role of Organizational Context on Digital Library's success factor, Emerging Trends and Challenges in Information Technol ogy Management, 712714.

[19] Davis, F. D. (1989). Perceived usefulness, perceived ease of use, and user acceptance of information technology. MIS Quarterly, 319-340.

[20] Delone, W. H., McLean, E., R. . (2003). The DeLone and McLean Model of Information Systems Success: A
Ten-Year Update. Journal of Management Information Systems, 19 (4) 9-30.doi:10.1080/07421222.2003.11045 748

[21] DeLone, W. H., McLean, E. R. (1992). Information systems success: The quest for the dependent variable. Information Systems Research, 3 (1) 60-95.

[22] DePietro, R., Wiarda, E., Fleischer, M. (1990). The context for change: Organization, technology and environment. In: L. G. Tornatzky \& M. Fleischer (Eds.), The processes of technological innovation (p. 151-175). Lexington, MA: Lexington Books.

[23] Espinoza-Parra, S., Molero, F., FusterRuizdeapodaca, M. J. (2015). Transformational leadership and job satisfaction of police officers (carabineros) in Chile: the mediating effects of group identification and work engagement/Liderazgo transformacional y satisfacción laboral en carabineros de Chile: los efectos mediadores de la identificación con el grupo y el work engagement. Revista de Psicología Social, 30 (3) 439-467.

[24] Fishbein, M., Ajzen, I. (1975). Belief, attitude, intention and behavior: An introduction to theory and research. MA: Addison-Wesley.

[25] Fox, E. A. (2002). Overview of digital library components and developments. Computer Science Technical Reports.

[26] Gatian, A. W. (1994). Is user satisfaction a valid measure of system effectiveness? Information \& management, 26 (3) 119-131.

[27] Glaser, B. G., Strauss, A. L. (1967). The Discovery of Grounded Theory; Strategies for Qualitative Research. Chicago, IL: Aldine Publishing.

[28] Goodhue, D. L., Thompson, R. L. (1995). Task-technology fit and individual performance. MIS Quarterly, 213236.

[29] Hong, W., Thong, J. Y., Wong, W.-M., Tam, K.-Y. (2002). Determinants of user acceptance of digital libraries: an empirical examination of individual differences and system characteristics. Journal of Management Information Systems, 18 (3) 97-124.

[30] Hwang, M. I., Thorn, R. G. (1999). The effect of user engagement on system success: a meta-analytical integration of research findings. Information \& Management, 35 (4) 229-236.

[31] Jiang, Y., Chen, D., Lai, F. (2010). Technologicalpersonal-environmental (TPE) framework: A conceptual model for technology acceptance at the individual level. Journal of International Technology and Information Management, 19 (3) 5.

[32] Johnson, D. M., Ferguson, J. A., Lester, M. L. (1999). Computer experiences, self-efficacy and knowledge of students enrolled in introductory university agriculture courses. Journal of Agricultural Education, 40, 28-37. 
[33] Jose, A. (2007). Evaluation of digital libraries: a case study. Proc. of Semantic Web \& Digital Lib, 229-238.

[34] Kai-ming Au, A., Enderwick, P. (2000). A cognitive model on attitude towards technology adoption. Journal of Managerial Psychology, 15 (4) 266-282.

[35] Karatepe, O. M., Karadas, G., Azar, A. K., Naderiadib, N. (2013). Does work engagement mediate the effect of polychronicity on performance outcomes? A study in the hospitality industry in Northern Cyprus. Journal of Human Resources in Hospitality \& Tourism, 12 (1) 52-70.

[36] Kiran, K., Diljit, S. (2012). Modeling web-based library service quality. Library \& Information Science Research, 34 (3) 184-196.

[37] Klopping, I. M., McKinney, E. (2004). Extending the technology acceptance model and the task-technology fit model to consumer e-commerce. Information Technology, Learning, and Performance Journal, 22 (1) 35.

[38] Koohang, A. (2004). Students' perceptions toward the use of the digital library in weekly web based distance learning assignments portion of a hybrid programme. British Journal of Educational Technology, 35 (5) 617-626.

[39] Lassila, K. S., Brancheau, J. C. (1999). Adoption and Utilization of Commercial Software Packages: Exploring Utilization Equilibria, Transitions, Triggers, and Tracks. Journal of Management Information Systems, 16(2) 63-90.

[40] MacMillan, A., Huff, B. (2009). Transforming Infoglut! A Pragmatic Strategy for Oracle Enterprise Content Management: McGraw-Hill, Inc.

[41] Mannix, K. (2010). Using Enterprise Content Management Principles to Manage Research Assets. Retrieved from http://www.aair.org.au/app/webroot/media/pdf/ AAIR\%20Fora/Forum\%202010/11-1Mannix.pdf

[42] Marchionini, G. (1990). Effects of search and subject expertise on information seeking in a hypertext environment. In: The Proceedings of the 53rd Annual Meeting of the ASIS, 1990.

[43] Marlin, S. (2005, 4 April). Content's Value Enhanced. Information Week. Retrieved from http:// www.informationweek.com/contents-value-enhanced/d/did/1036785?page_number=2

[44] Maslach, C., Leiter, M. P. (1997). The truth about burnout: How organizations cause personal stress and what to do about it. San Francisco, CA: Wiley.

[45] Masrek, M. N. (2007). Measuring campus portal effectiveness and the contributing factors. CampusWideInformation Systems, 24 (5) 342-354.

[46] Masrek, M. N., Gaskin, J. E. (2016). Assessing users satisfaction with web digital library: the case of Universiti Teknologi MARA. The International Journal of Information and Learning Technology, 33(1) 36-56.

[47] Masrek, M. N., Jamaludin, A., Awang Mukhtar, S.
(2010). Evaluating academic library portal effectiveness: A Malaysian case study. Library Review, 59 (3) 198-212.

[48] Masrek, M. N., Karim, N. S. A., Hussein, R. (2007). Antecedents and Impact of intranet utilization: A conceptual framework. Journal of Information Technology Impact, 7(3).

[49] Masrek, M. N., Samadi, I. (2017). User engagement in academic web digital library. International Journal of Civil Engineering and Technology, 8 (9) 789-799.

[50] Matusiak, K. K. (2012). Perceptions of usability and usefulness of digital libraries. International journal of humanities and arts computing, 6 (1-2) 133-147.

[51] O'Brien, H. L., Toms, E. G. (2010). The development and evaluation of a survey to measure user engagement. Journal of the Association for Information Science and Technology, 61(1) 50-69.

[52] O'Callaghan, R., Smits, M. (2005). A strategy development process for enterprise content management. 2005 European Conference on Information Systems, 148.

[53] Park, N., Roman, R., Lee, S., Chung, J. E. (2009). User acceptance of a digital library system in developing countries: An application of the Technology Acceptance Model. International Journal of Information Management, 29 (3) 196-209.

[54] Pembee, P. K. (2014). Factors influencing the use of library information systems by staff and students in Kabarak University. (Master Thesis), Kabarak University, Kabarak University, Kenya.

[55] Poude, L. D., Zamani, B. E., Abedi, A. (2011). Relation between Iranian students' attitudes subscales with the kind of internet usage in universities. Procedia-Social and Behavioral Sciences, 15, 2694-2698.

[56] Rahman, A. L. A., Jamaludin, A., Mahmud, Z. (2011). Intention to use digital library based on modified UTAUT model: Perspectives of Malaysian postgraduate students. International Journal of Information and Communication Engineering, 5 (3).

[57] Ramayah, T., Aafaqi, B. (2004). Role of self-efficacy in e-library usage among students of a public university in Malaysia. Malaysian Journal of Library \& Information Science, 9 (1) 39-57.

[58] Rustagi, S., King, W. R., Kirsch, L. J. (2008). Predictors of formal control usage in IT outsourcing partnerships. Information Systems Research, 19(2) 126-143.

[59] Sahak, M. D., Masrek, M. N. (2014). Library Usage of Medical Students: A Comparative Analysis of First Year and Third Year Students in Universiti Putra Malaysia. Procedia-Social and Behavioral Sciences, 129, 127-132.

[60] Samadi, I. (2016). Determinants and Impacts of Digital Library Usage: A Survey Among Selected Iranian Universities. (Doctor of Philosophy (Information Management)), Universiti Teknologi MARA Puncak Perdana, Shah Alam. 
[61] Samadi, I., Masrek, M. N., Yatin, S. (2014). The effect of individual characteristics and digital library characteristics on digital library effectiveness: A survey at University of Tehran. World Applied Sciences Journal, 30 (30 A) 214-220.

[62] Saracevic, T. (2004). Evaluation of digital libraries: An overview. In: Notes of the DELOS WP7 workshop on the evaluation of Digital Libraries, Padua, Italy.

[63] Schaufeli, W. B., Bakker, A. B., Salanova, M. (2006). The measurement of work engagement with a short questionnaire: A cross-national study. Educational and psychological measurement, 66 (4) 701-716.

[64] Simon, S. J., Grover, V., Teng, J. T. C., Whitcomb, K. (1996). The Relationship of Information System Training Methods and Cognitive Ability to End-user Satisfaction, Comprehension, and Skill Transfer: A Longitudinal Field Study. Information systems research, 7 (4) 466-490.

[65] Smith, A. (2002). Strategies for building digitized collections. Microform \& Imaging Review, 31 (1) 8-30.

[66] Tait, P., Vessey, I. (1988). The effect of user involvement on system success: a contingency approach. MIS Quarterly, 91-108.

[67] Thong, J. Y., Hong, W., Tam, K.-Y. (2002). Understanding user acceptance of digital libraries: what are the roles of interface characteristics, organizational context, and individual differences? International Journal of Human-Computer Studies, 57 (3) 215-242.

[68] Trice, A. W., Treacy, M. E. (1988). Utilization as a dependent variable in MIS research. ACM SIGMIS Database: The Database for advances in information systems, 19 (3-4) 33-41.

[69] Trivedi, M. (2010). Digital libraries: functionality, usability, and accessibility. Library Philosophy and Practice (e-journal) 381.

[70] Vaidyanathan, G., Sabbaghi, A., Bargellini, M. (2005). User acceptance of digital library: An empirical exploration of individual and system components. Issues in Information Systems, 6 (2) 279-285.

[71] Valacich, J., Schneider, C. (2010). Information systems today: managing in the digital world (4 ed.). New Jersey: Prentice Hall.

[72] Venkatesh, V., Morris, M. G., Davis, G. B., Davis, F. D. (2003). User acceptance of information technology: Toward a unified view. MIS Quarterly, 425-478.

[73] Volovici, R., Fratila, A., Bera, L. G., Moisil, I. (2017). Digital Libraries Impact on Students' Learning Behaviour. Case Study: Medical Students. Qualitative and Quantitative Methods in Libraries, 5 (1) 23-29.

[74] Wan Dollah, W. A. K. (2006). Digital reference services in selected public academic libraries in Malaysia: A case study. In: The Asia-Pacific Conference on Library \& Information Education \& Practice 2006, Singapore.

[75] Webster, J., Watson, R. T. (2002). Analyzing the past to prepare for the future: Writing a literature review. Management Information Systems Quarterly, 26(2) 3.

[76] Witten, I. H., Bainbridge, D., Nichols, D. M. (2010). How to build a digital library (2 ed.). United States of America: Morgan Kaufmann.

[77] Xanthopoulou, D., Bakker, A. B., Demerouti, E., Schaufeli, W. B. (2007). The role of personal resources in the job demands-resources model. International journal of stress management, 14 (2) 121.

[78] Xanthopoulou, D., Bakker, A. B., Demerouti, E., Schaufeli, W. B. (2009). Work engagement and financial returns: A diary study on the role of job and personal resources. Journal of occupational and organizational psychology, 82 (1) 183-200.

[79] Xu, F., Du, J. T. (2018). Factors influencing users' satisfaction and loyalty to digital libraries in Chinese universities. Computers in Human Behavior, 83, 64-72. doi:https://doi.org/10.1016/j.chb.2018.01.029.

\section{Author biographies}

Mohamad Rahimi Mohamad Rosman is a senior lecturer and Ph.D. candidate at the Department of Information System Management, Faculty of Information Management, Universiti Teknologi MARA Kelantan Branch, MALAYSIA. His research interest includes information system management, system development methodologies, digital library engagement, enterprise content management system, web development and programming, and disruptive technologies. Mohamad Rahimi Mohamad Rosman is the corresponding author and can be contacted at: rahimimr@kelantan.uitm.edu.my

Mohd Nasir Ismail is an Associate Professor at the Department of Information System Management, Faculty of Information Management, Universiti Teknologi MARA Kelantan Branch, MALAYSIA. His research interest includes information system management, instructional design, and knowledge management. E-mail: nasir733@kelantan.uitm.edu.my

Mohamad Noorman Masrek is an Associate Professor at the Department of Information System Management, Faculty of Information Management, Universiti Teknologi MARA Shah Alam, MALAYSIA. His research interest includes information system development, system development methodologies, Intranet and Internet technologies. E-mail: mnoorman@salam.uitm.edu.my 